
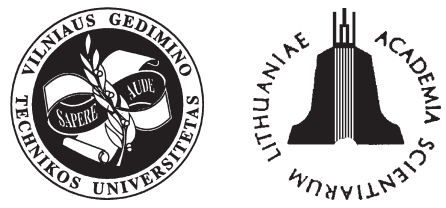

ISSN 1648-4142 TRANSPORT

www.transport.vtu.lt

TRANSPORT - 2005, Vol XX, No 4, 141-145

\title{
INVESTIGATION OF THE INTERACTION OF AN AUTOMOBILE WHEEL WITH A VERTICAL OBSTACLE
}

\author{
Edgar Sokolovskij \\ Dept of Transport Technological Equipment, \\ Vilnius Gediminas Technical University, \\ Plytines g. 27, LT-10105 Vilnius-16, Lithuania.E-mail:ESokolovskij@hotmail.com
}

Received 2005-01-15; accepted 2005-05-25

\begin{abstract}
Collision of automobile wheels with a vertical obstacle as a result of which the wheel tire gets dismantled is considered in the present article. The required force and the minimal speed of driving which is equivalent to the expenditures of the kinetic energy necessary for dismantling of the tire from the wheel rim after the collision with an obstacle are ascertained. The values of this force and speed typical of automobiles attributed to different classes, their dependence upon the height of the obstacle and the angle of collision with the obstacle are fixed. A more precise method for the calculation of the automobile speed prior to the traffic accident taking into consideration the expenditures of the kinetic energy necessary for dismantling of the wheel after the occurrence of its collision with a vertical obstacle is suggested.
\end{abstract}

Keywords: interaction, wheel, automobile, vertical obstacle, tire, dismantling, equivalent speed.

\section{Introduction}

Automobile movement when its wheels collide with an obstacle is usually considered in the literary sources, whereas the automobile movement when the side of its wheel collides with a vertical obstacle is less investigated [1-4]. Seeking for more practical application of the results of these investigations (for example, while carrying out the examination of traffic accidents and while fixing the speed of the automobile movement prior to the traffic accident more precisely), it is necessary to fix the speed of the automobile movement which is equivalent to the expenditures of the automobile kinetic energy at the moment of collision of the automobile side with a vertical obstacle.

The investigation of damages of automobile wheels which have occurred in the traffic accident proves that one of the most often occurred damage of the wheels, i.e. the mounting sides of the tire displaced from the edges of the rim usually occurs in the course of the traffic accident after the wheel has collided with hard objects, for example, a board [5, 6]. The automobile looses a part of its kinetic energy and speed at the moment of collision. Up to now, while rating the speed of the automobiles before the traffic accidents, usually the expenditures of the automobile kinetic energy and loss of its speed have not been taken into consideration $[7,8]$. Thus, sometimes the reduced values of the automobile speed have been obtained. Seeking to rate the automobile speed before the occurrence of the traffic accident more precisely it is necessary to evaluate the amount of kinetic energy of the automobile or the automobile speed which is equivalent to the expenditure of its kinetic energy which was present and caused the above mentioned damage of the wheel at the moment of its collision with an obstacle (for example, a border).

\section{Theoretical investigation}

When an automobile slides sideways and the side components of its wheels collide with a vertical obstacle (for example, a border), the area of the contact of the wheel with this obstacle makes the segment (Fig 1).

So to dismantle the tire the outside force $F_{i \check{s}}$, which produces an impact on it, should be larger than the force $F_{d}$, which is composed of two constituents, i.e. the force which is necessary to cope with the inside pressure of the tire and the force which is necessary to cope with friction of the mounting side and the rim.

Having carried out the theoretical investigation $[5,9]$, the condition of dismantling of the tire from the rim was obtained: 


$$
\begin{aligned}
& F_{i \check{s}}>F_{d}=\frac{R^{2}}{2}\left(\frac{\pi \alpha}{180}-\sin \alpha\right) . \\
& \frac{p\left(\pi R^{2}-\pi r^{2}\right) b}{\left.\left(\pi R^{2}-\pi r^{2}\right) b-\frac{R^{2}}{2}\left(\frac{\pi \alpha}{180}-\sin \alpha\right)\right)_{d}}+m g f,
\end{aligned}
$$

or

$$
\begin{aligned}
& F_{i \breve{s}}>F_{d}=\frac{1}{2}(l R-a(R-h)) . \\
& \frac{p\left(\pi R^{2}-\pi r^{2}\right) b}{\left(\pi R^{2}-\pi r^{2}\right) b-\frac{1}{2}(l R-a(R-h)) l_{d}}+m g f,
\end{aligned}
$$

where $R$ - the external radial of the wheel, $\mathrm{m} ; \alpha$ - the angle of the sector obtained by connecting the edge dots of the segment of the contact area with the centre of the wheel, deg. (Fig 1); $p$ - the pressure of the undamaged tire, $\mathrm{Pa} ; r$ - the internal radial of the tire (the external radial of the wheel rim), $\mathrm{m} ; b$ - the width of the tire, $\mathrm{m} ; l_{d}$ - the distance which is necessary to remove the tire from the edge of the wheel rim to be dismantled, $\mathrm{m}$ (Fig 2); $m$ - the weight of the automobile, $\mathrm{kg} ; g$ - the acceleration of the free drop, $\mathrm{m} / \mathrm{s}^{2} ; f-$ the conventional coefficient of friction of the mounting side of the tire and the wheel rim; $l$ - a part of the rim located in between the edge dots of the segment of the contact area by measuring the external perimeter of the wheel, m (Fig 1); $a$ - the length of the straight line which connects the edge dots of the segment of the contact area, m (Fig 1$) ; h$ - the height of the vertical obstacle, $\mathrm{m}$.

However, while carrying out the job practically (for example, while carrying out the examination of traffic accidents), not the force which is necessary for dismantling of the tire should be known, but the speed

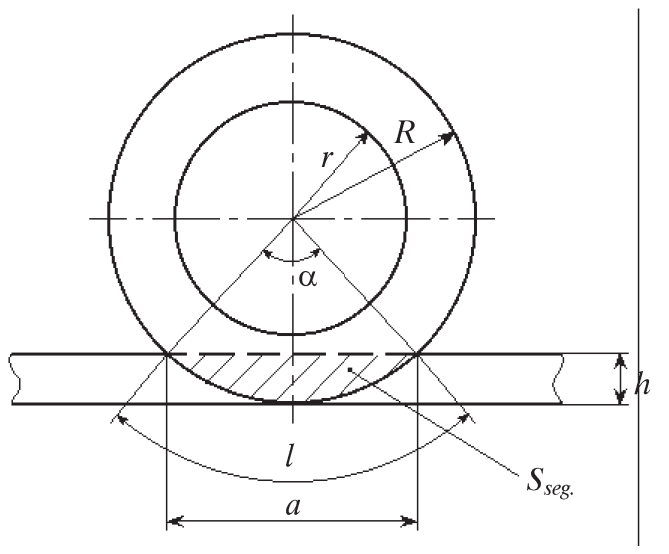

Fig 1. The contact of the side component of an automobile wheel with a vertical obstacle

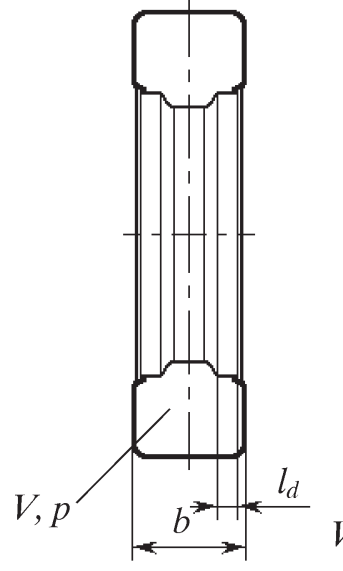

a)

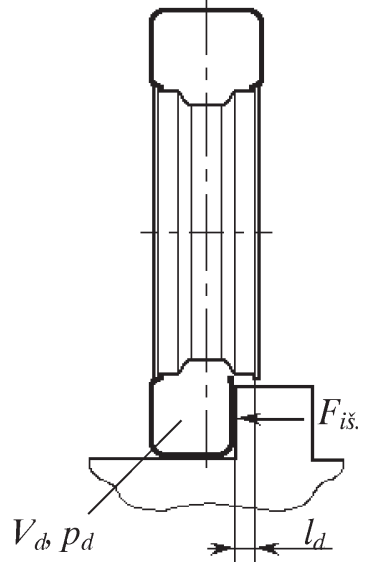

b)
Fig 2. The automobile wheel: a - before the collision with a vertical obstacle; $b$ - at the moment of collision just before tire dismantling

of the automobile movement $v_{E}$, which is equivalent to the expenditures of its kinetic energy used for dismantling of the tire from the wheel $\mathrm{rim}(\mathrm{m} / \mathrm{s})$ :

$v_{E}=\sqrt{\frac{2}{m} A_{d}}=$

$\sqrt{\frac{2 l_{d}}{m}\left(\frac{R^{2}}{2}\left(\frac{\pi \alpha}{180}-\sin \alpha\right) \frac{p\left(\pi R^{2}-\pi r^{2}\right) b}{\left(\pi R^{2}-\pi r^{2}\right) b-\frac{R^{2}}{2}\left(\frac{\pi \alpha}{180}-\sin \alpha\right) l_{d}}+m g f\right)}$,

or

$v_{E}=$

$\sqrt{\frac{2 l_{d}}{m}\left(\frac{1}{2}(l R-a(R-h)) \frac{p\left(\pi R^{2}-\pi r^{2}\right) b}{\left(\pi R^{2}-\pi r^{2}\right) b-\frac{1}{2}(l R-a(R-h)) l_{d}}+m g f\right)}$

where $A_{d}$ - the job on dismantling the tire from the wheel rim, J.

It's a usual case when the values of the angle $\alpha$, as well as the distance $a$ and the length of the rim $l$ are not known. Thus, they can be expressed by other known values (Fig 1):

$$
\begin{aligned}
& \alpha=2 \arccos \left(\frac{R-h}{R}\right) ; \\
& a=2 \sqrt{R^{2}-(R-h)^{2}}=2 \sqrt{2 R h-h^{2}} ; \\
& l=\frac{\pi R}{180} 2 \arccos \left(\frac{R-h}{R}\right)
\end{aligned}
$$

Knowing the minimal speed $v_{E}$, which is equivalent to the expenditures of the automobile kinetic 
energy necessary for dismantling of the tire from the rim in cases when an automobile, sliding to the side, collides with a vertical obstacle (for example, a border) and the automobile wheel becomes depressurized through the displaced mounting side of the tire, it is possible to calculate more precisely the automobile speed before the occurrence of the traffic accident $(\mathrm{km} / \mathrm{h})$ evaluating the expenditures of kinetic energy necessary for dismantling of the tires:

$$
v_{a}=\sqrt{26\left(S_{1} j_{1}+\ldots+S_{i} j_{i}\right)+v_{s}^{2}+v_{E}^{2} z}
$$

where $S_{1 \ldots i}$ - the distance which was covered by the automobile which has been sliding along the certain road-cover, $\mathrm{m} ; j_{1 . . i}$ - the deceleration of the automobile which has been sliding along the certain roadcover, $\mathrm{m} / \mathrm{s}^{2} ; v_{s}-$ the automobile speed equivalent to the expenditures of its kinetic energy at the moment of its collision with the other object, for example, an automobile, $\mathrm{km} / \mathrm{h} ; v_{E}$ - the automobile speed equivalent to the expenditures of its kinetic energy necessary for dismantling of the tire from the rim, $\mathrm{km} / \mathrm{h} ; z-$ the number of the dismantled wheels.

\section{Results of the investigation}

The minimal force necessary for dismantling of the tire from the rim and the minimal speed of the automobile equivalent to the expenditures of its kinetic energy after the automobile straightforwardly collides with a vertical obstacle, when the tire is dismantled, have been calculated for definite automobiles of different types, i.e. HONDA CIVIC, MAZDA 626 and VW TRANSPORTER. The results are presented in Figs 3 and 4.

As we see, the above-mentioned force and speed increase with the increase of the height of the obstacle; larger values are typical of the automobiles with larger mass.

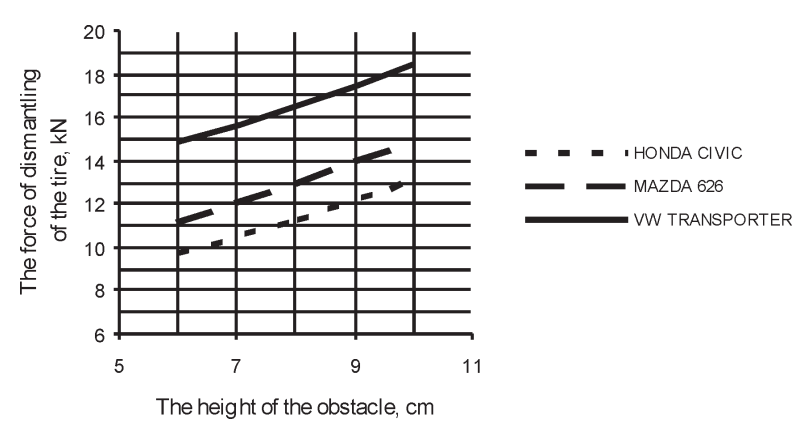

Fig 3. Minimal force necessary for dismantling of the tire from the rim

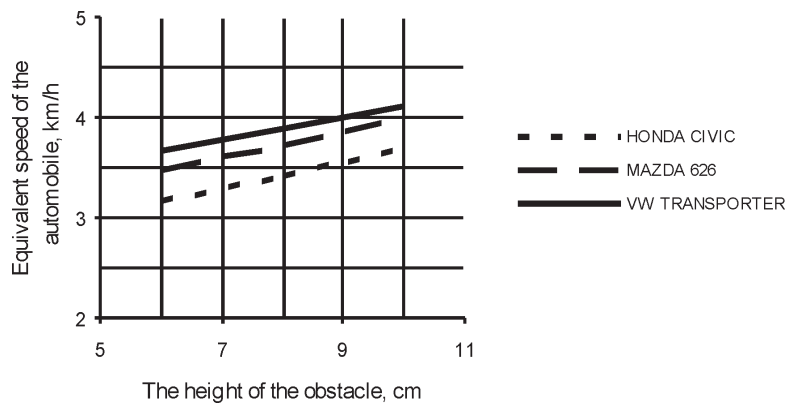

Fig 4. Automobile minimal speed equivalent to the expenditures of its kinetic energy at the moment of its collision with a vertical obstacle when the tire becomes dismantled

The dependence of the force necessary for dismantling of the tire from the rim and of the automobile speed equivalent to the expenditures of kinetic energy of the automobile at the moment of its collision with a vertical obstacle when the tire is dismantled, upon the angle of collision has been ascertained (for the height of the obstacle equal to 6,8 and $10 \mathrm{~cm}$ ). The results are presented in Figs 5-10.

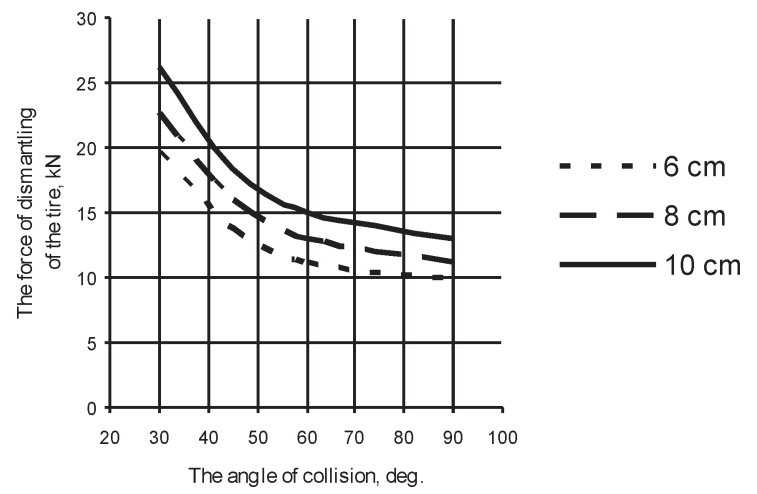

Fig 5. Dependence of the force necessary for dismantling of the tire from the rim upon the angle of collision for the automobile HONDA CIVIC

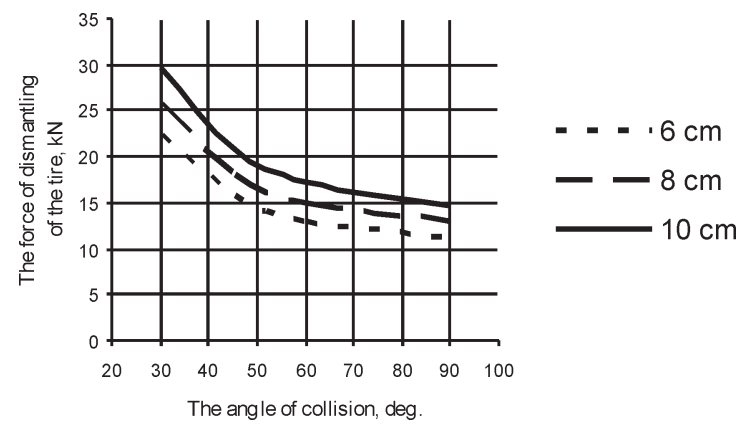

Fig 6. Dependence of the force necessary for dismantling of the tire from the rim upon the angle of collision for the automobile MAZDA 626 


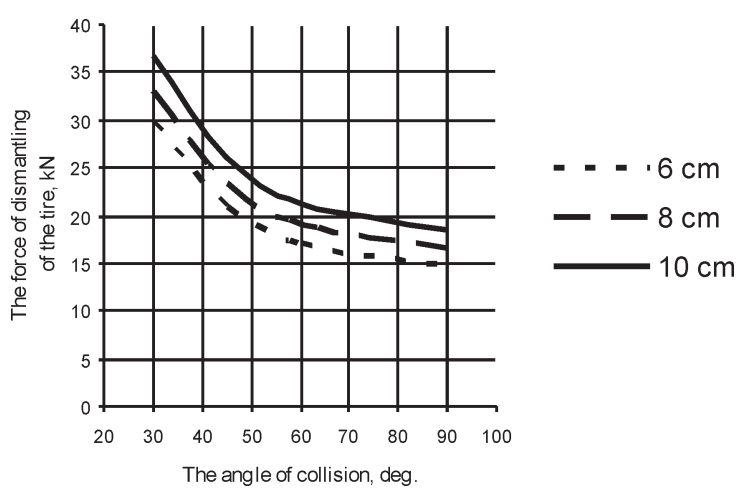

Fig 7. Dependence of the force necessary for dismantling of the tire from the rim upon the angle of collision for the automobile VW TRANSPORTER

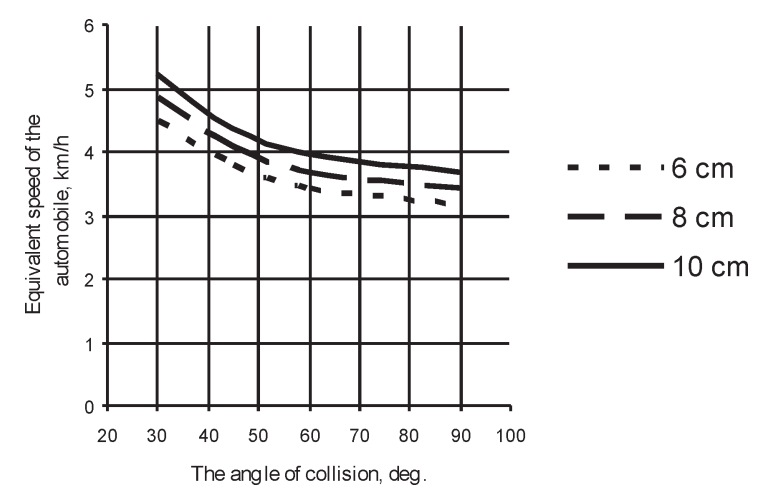

Fig 8. Dependence of the minimal automobile speed equivalent to the expenditures of its kinetic energy at the moment of collision with a vertical obstacle when the tire becomes dismantled upon the angle of collision for the automobile HONDA CIVIC

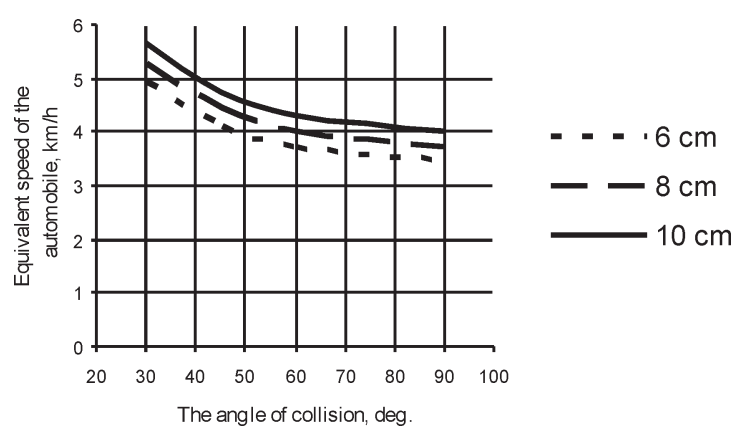

Fig 9. Dependence of the minimal automobile speed equivalent to the expenditures of its kinetic energy at the moment of collision with a vertical obstacle when the tire becomes dismantled upon the angle of collision for the automobile MAZDA 626

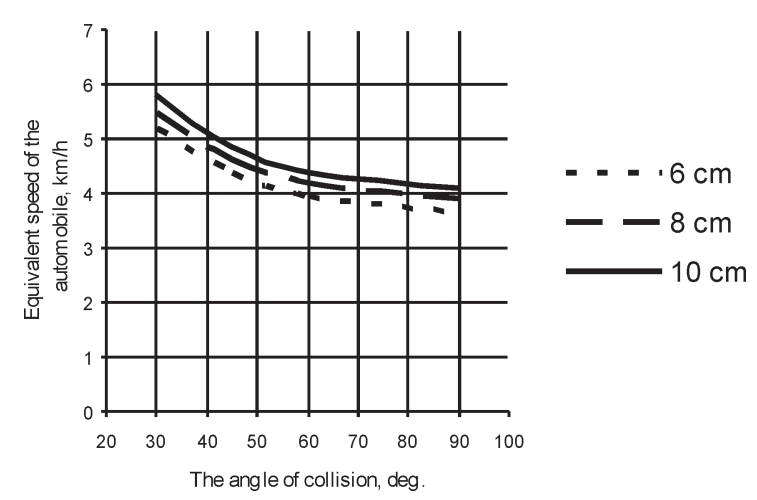

Fig 10. Dependence of the minimal automobile speed equivalent to the expenditures of its kinetic energy at the moment of collision with a vertical obstacle when the tire becomes dismantled upon the angle of collision for the automobile VW TRANSPORTER

It should be stated that the force necessary for dismantling of the tire from the rim and the speed equivalent to the expenditures of the automobile kinetic energy necessary for dismantling of the tire from the rim which was calculated, are minimal as, while calculating, the amount of kinetic energy which is consumed in the course of distortion of the tire carcass as well as in cases when the rim contacts the obstacle and causes the damage has not been evaluated.

\section{Conclusions}

1. Having created the methods of calculation of the minimal force necessary for dismantling of the tire from the rim and the automobile speed which is equivalent to the expenditures of its kinetic energy necessary for dismantling of the tire after the wheel has collided with a vertical obstacle, the dependence of this force and speed upon the height of the obstacle (Figs 3 and 4) and the angle of collision of the automobile with the vertical obstacle (Figs 5-10) for the automobiles of different classes (HONDA CIVIC, MAZDA 626 and VW TRANSPORTER) has been ascertained.

2. The values of the force which is necessary for dismantling of the tire from the wheel rim and of the speed which is equivalent to the expenditures of the automobile kinetic energy necessary for dismantling of the tire from the wheel rim which are calculated according to the offered methods, can serve as minimal possible values as, while calculating, the amount of kinetic energy which is consumed in the course of distortion of the tire carcass as well as in cases when the rim contacts an obstacle and causes the damage, has not been evaluated. 
3. The offered methods provide the possibility to calculate more precisely the speed of the automobile movement prior to the traffic accident by evaluating the expenditures of the kinetic energy used for dismantling of the tires when the automobile slides in the transversal direction and collides with a vertical obstacle (for example, a border) and the automobile wheel becomes hermetically unsealed through displacement of the mounting side of the tire. However, the application of the offered methods in the examination practice is quite complicated as, in the course of examination of traffic accidents, the expert is not very often aware of many values which are necessary for calculation.

\section{References}

1. Danner, M.; Halm, J. Technical analysis of road accidents (Technische analyse von Verkehrsunfällen). Eurotax (International) AG CH-8808 Pfäffikon, 1994. 570 p. (in Germany).

2. Lanzendoerfer, J.; Szczepaniak, C.; Szosland, A. Theory of automobile move (Teoria ruchu samochodu). Łódź: Wydawnictwo politechniki łódzkiej, 1988. 340 p. (in Poland).

3. Bogdevičius, M.; Prentkovskis, O.; Vladimirov, O. Engineering solutions of traffic safety problems of road transport. Transport, 2004, Vol XIX, No 1, p. 43-50.
4. Prentkovskis, O. Interaction between the vehicle and obstacles: Doctoral Dissertation, Technological Sciences, Transport Engineering (Automobilio sąveika su kliūtimis: Daktaro disertacija). Vilnius: VGTU, 2000. 117 p. (in Lithuanian).

5. Sokolovskij, E. Investigation of interaction of the wheel with the road and its elements in the context of examination of traffic accidents. Doctoral Dissertation (Rato sąveikos su keliu ir jo elementais tyrimai eismo ịvykių ekspertizès kontekste. Daktaro disertacija). Vilnius: VGTU, 2004. 147 p. (in Lithuanian).

6. Sokolovskij, E. The analysis and statistical research of damages of car wheels appearing just before and during an accident. Transport Engineering (Transportas), 2000, Vol XV, No 3, p. 118-122 (in Lithuanian).

7. Ilarionov, V. A. Examination of road traffic accidents (Экспертиза дорожно-транспортных происшествий). Moscow: Transport, 1989. 254 p. (in Russian).

8. Lukoševičienè, O. The accident analysis and simulation. Monograph (Autoịvykių analize ir modeliavimas. Monografija). Vilnius: Technika, 2001. 244 p. (in Lithuanian).

9. Korn, G.; Korn, T. Reference Book on Mathematics for Scientific Workers and Engineers (Справочник по математике для научных работников и инженеров). Moscow: Nauka, 1968. 720 p. (in Russian). 